\title{
Procoagulant Platelets: Mechanisms of Generation and Action
}

\author{
N.A. Podoplelova ${ }^{1,2}$ D.Y. Nechipurenko ${ }^{1,2,3}$ A.A. Ignatova ${ }^{1,2}$ A.N. Sveshnikova ${ }^{1,2,3}$ \\ M.A. Panteleev $1,2,3$
}

${ }^{1}$ Center for Theoretical Problems of Physicochemical Pharmacology, Russian Academy of Sciences, Moscow, Russia

2 National Medical Research Center of Pediatric Hematology, Oncology and Immunology named after Dmitry Rogachev, Moscow, Russia

${ }^{3}$ Faculty of Physics, Lomonosov Moscow State University, Moscow, Russia

Address for correspondence Prof. Mikhail A. Panteleev, Center for Theoretical Problems of Physicochemical Pharmacology, Russian Academy of Sciences, 30 Srednyaya Kalitnikovskaya Str., Moscow 109029, Russia (e-mail: mapanteleev@yandex.ru).

Hämostaseologie 2021;41:146-153.

\begin{abstract}
Keywords

- procoagulant platelets

- thrombosis

- hemostasis

During the past decades, it has been increasingly recognized that the major function of accelerating membrane-dependent reactions of blood coagulation is predominantly implemented by a subset of activated platelets. These procoagulant platelets (also called collagen- and thrombin-activated or COAT, coated, necrotic, although there could be subtle differences between these definitions) are uniquely characterized by both procoagulant activity and, at the same time, inactivated integrins and profibrinolytic properties. The mechanisms of their generation both in vitro and in situ have been increasingly becoming clear, suggesting unique and multidirectional roles in hemostasis and thrombosis. In this mini-review, we shall highlight the existing concepts and challenges in this field.
\end{abstract}

\section{Introduction}

Platelets play several physiological roles, but their two major contributions to hemostasis and thrombosis are believed to be based on the two abilities: to form aggregates and to support membrane-dependent reactions of coagulations upon activation. ${ }^{1}$ For many years, it was believed that these two abilities are manifested by activated platelets uniformly. ${ }^{2}$ Even though pioneering findings of phosphatidylserine (PS) expression by a separate platelet subpopulation could be traced as early as $1990 \mathrm{~s}^{3}{ }^{3}$ the explosive development of the field began 10 years later with the report on procoagulant COAT platelets by Alberio et $\mathrm{al}^{4}$ that paradoxically have low levels of active integrins. ${ }^{5}$ Only in the past decade, the exciting fact that platelets upon activation get segregated into at least two subpopulations, each assuming one of the two earlierdescribed major functions, has become widely accepted. ${ }^{6-8}$ Although many mysteries of the generation, functional properties, physiological roles, and clinical significance of platelet subpopulation remain to be deciphered, the recent years witnessed an explosive growth of studies addressing some of these issues (see recent reviews ${ }^{6,7,9-11}$ ). In this mini-review, we shall highlight the existing concepts and challenges in this field.

\section{Procoagulant Platelets: What Are They?}

Platelets, in addition to the usual variability in size and number of molecules/organelles, also have morphological and functional differences. Back in the 1960s, morphological differences in platelets subjected to hypotonic stress were described. ${ }^{12}$ In addition, at the end of the 1990s, using flow cytometry, it was shown that Annexin V (a specific marker of PS) does not bind to all platelets activated by thrombin with collagen. ${ }^{3}$ Also it has been shown that, upon adhesion to collagen, about half of the platelets bind to annexin V, while the addition of thrombin increases the proportion of such cells to $80 \%{ }^{13}$ It was found that activation by thrombin with received

December 15, 2020

accepted after revision

February 25, 2021 (c) 2021. Thieme. All rights reserved. Georg Thieme Verlag KG,

Rüdigerstraße 14,

70469 Stuttgart, Germany
DOI https://doi.org/ 10.1055/a-1401-2706. ISSN 0720-9355. 
DIC

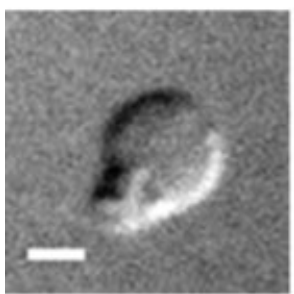

DIC

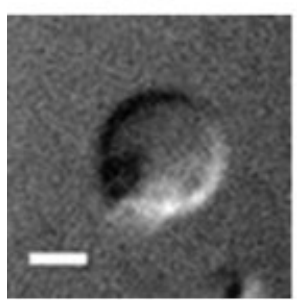

DIC

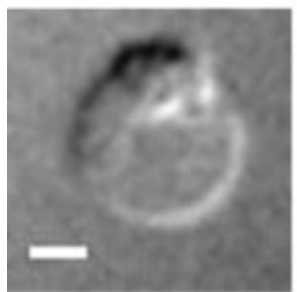

DIC

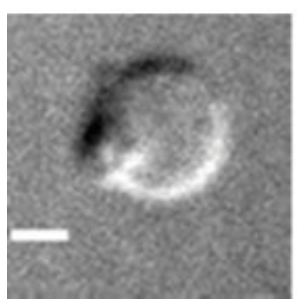

Annexin V

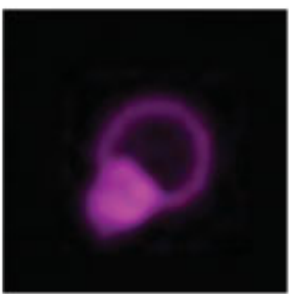

Annexin V

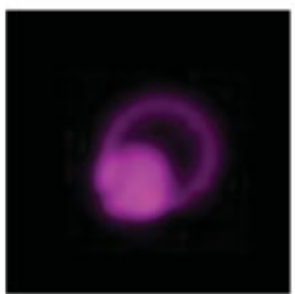

Annexin V

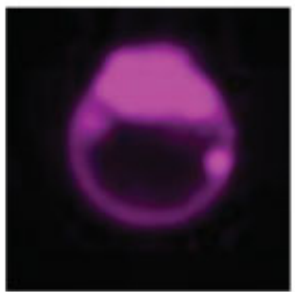

Annexin V

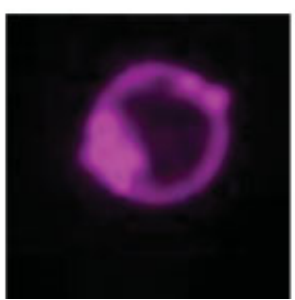

CD62p

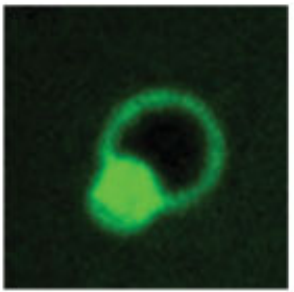

Fibrinogen

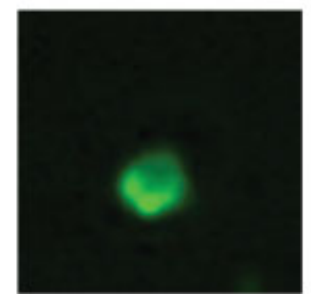

Thrombospondin

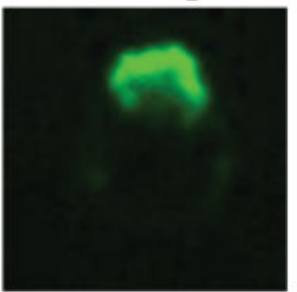

Factor V

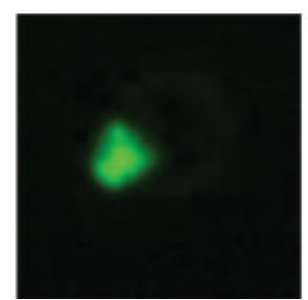

Overlay

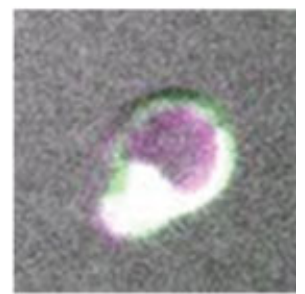

Overlay
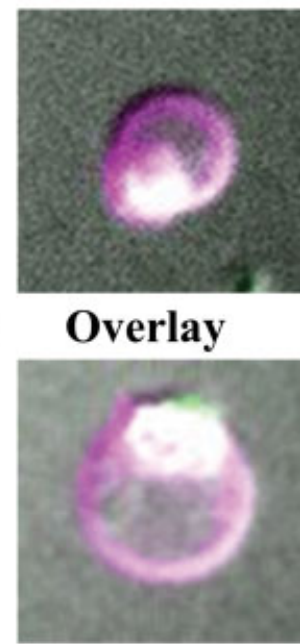

Overlay

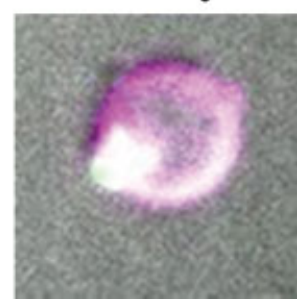

Fig. 1 Distribution of $\alpha$-granule proteins on the procoagulant platelets. Platelets from healthy donors were activated at $50,000 \mu \mathrm{L}^{-1}$ with $100 \mathrm{nM}$ of thrombin and $20 \mu \mathrm{g} / \mathrm{mL}$ of CRP, dual labeled with annexin $\mathrm{V}$, and with indicated antibodies, and imaged with confocal microscopy. ${ }^{14,88}$ Representative confocal images of DIC; Alexa647 (magenta) fluorescence of annexin V; and FITC (green) fluorescence of anti-CD62p, anti-fibrin (ogen), anti-thrombospondin, or anti-factor $V$ antibody are shown. Scale bar, $2 \mu \mathrm{m}$.

collagen results in a subpopulation of cells expressing the $\alpha$-granular protein factor $\mathrm{V}$ on their surface. ${ }^{4}$ In addition, the same subpopulation of cells is characterized by the presence of PS on the outer leaflet of the membrane, and also binds to other $\alpha$-granular proteins (fibrinogen, von Willebrand factor, thrombospondin, fibronectin, and $\alpha_{2^{-}}$ antiplasmin). ${ }^{5}$ It was shown that $\alpha$-granular proteins are nonuniformly distributed on the platelet membrane, and are concentrated only in its small area (- Fig. 1). ${ }^{14-17}$ Despite the large number of works devoted to platelet subpopulations, only by the end of the 2000s, the phenomenon of the separation of platelet subpopulations was finally recognized. However, there is still no common name for subpopulations. ${ }^{6,7}$

It was believed that only PS-negative platelets are able to aggregate, because they have active $\alpha \operatorname{IIb} \beta 3$ integrin on their surface. ${ }^{5,18}$ There is evidence in the literature that inhibition of the formation of PS-positive platelets leads to an increase in the rate of platelet plugs growth in flow chambers, and the adhesion of nonactivated platelets to the activated monolayer is significantly reduced if there are PS-positive cells in the monolayer. ${ }^{19}$ More recent studies have shown that PS-positive platelets cannot aggregate with each other but can be recruited into aggregates by PS-negative platelets. ${ }^{20}$ However, the main function of PS-positive platelets appears to support the plasma coagulation reactions. Rest platelets cannot to promoting coagulation reactions. Although some coagulation factors can also bind to inactivated platelets, active enzymatic complexes do not appear in this case. ${ }^{21}$ Only after strong activation negatively charged phospholipids, primarily PS, appear on the outer leaflet of cell membrane.

Several studies have shown that coagulation factors are mainly associated with PS-positive platelets. ${ }^{22-24}$ And it is on the surface of these platelets that the main processes of plasma coagulation are performed: activation of a complex of factors $\mathrm{X}$ and prothrombin of intrinsic tenase (from factors 
VIIIa and IXa associated with the phospholipid membrane) and prothrombinase (from factors Va and Xa associated with the phospholipid membrane), respectively.

Another important question is where PS-positive platelets go after they have completed their function. Our body has mechanisms for removing dead cells, both apoptotic and necrotic. However, it is still not completely clear whether these mechanisms apply to platelets. It was shown that lactadherin could mediate the clearance of platelet-derived PS-positive microvesicles, ${ }^{25}$ but whether they mediate the clearance of PS-positive platelets remains to be fully elucidated.

\section{Procoagulant Platelets Generation and Signal Transduction}

The pioneering studies reported that procoagulant platelets are formed upon potent dual stimulation with collagen and thrombin, which was one of the reasons for the name COAT. ${ }^{3-5}$ Later reports suggested that two distinct subpopulations can be observed with thrombin alone ${ }^{23}$ or PAR1 (protease-activated receptors) and/or PAR4 thrombin receptor agonist peptide ${ }^{24,26}$ stimulation as well, although their fraction does not usually exceed 10 to $20 \%$ compared with 30 to $60 \%$ and more for dual stimulation. Other properties including balloon-like morphology, coagulation factor binding, the presence of the "coat" of $\alpha$-granule proteins of the thrombin-produced procoagulant platelets appear similar to those produced by dual stimulation. ${ }^{14,27}$ Thrombin's enzymatic activity is essential, in particular, for the formation of the $\alpha$-granular protein "coat." ${ }^{14,28}$ Adenosine diphosphate is not considered a strong agonist by itself, but was shown to significantly modulate, via $\mathrm{P}_{2} \mathrm{Y}_{12}$ receptor, the number of procoagulant platelets produced in response to other agonists. ${ }^{27,29-31}$ The role of other signaling receptors is not clear. To summarize, it is currently believed that procoagulant platelets are mainly produced by either thrombin (via PAR1 [or PAR3 for murine platelets] and PAR4) or collagen (via glycoprotein $\mathrm{VI}$ ) stimulation, with ADP acting as a modulator via $\mathrm{P} \mathrm{Y}_{12}$. Instead of collagen, which is very difficult during in vitro studies, convulxin ${ }^{4,32}$ or collagenrelated peptides ${ }^{33}$ are often used. It should be noted that recent studies suggest that not only collagen and its analogs but other molecules such as polymerized fibrin may cause procoagulant platelet formation via glycoprotein $\mathrm{VI}^{34}$

With regards to intracellular events, it was found quite early that high, sustained cytosolic calcium concentrations (and not single or even serial calcium spikes) are needed for procoagulant platelets to be formed, ${ }^{13}$ but it took some time to figure out the mechanisms responsible for different scenarios of calcium signaling. The critical regulator of procoagulant platelet formation turned out to be mitochondrial permeability transition pore (MPTP) opening, ${ }^{35}$ and the pathway to procoagulant platelet formation upon stimulation was found to be caspase independent. ${ }^{36}$ Beginning from this stage, the use of mice knockouts (in cyclophilin D, mitochondrial calcium uniporter (MCU), and anoctamin 6 as well as in Scott's syndrome patients, ${ }^{26,29,37}$ single-cell microscopy of shape change, calcium signaling and mitochondrial potential monitoring, ${ }^{15,38-40}$ imaging flow cytometry, ${ }^{41}$ and continuous flow cytometry ${ }^{26,42,43}$ and the use of low-affinity calcium dyes ${ }^{44}$ allowed significant insights into the nature of procoagulant platelet generation upon stimulation.

The current concept suggests that procoagulant platelet generation begins with classic cytosolic calcium increase, which is caused by its efflux from internal stores in its turn induced by inositol triphosphate released by phospholipase C action at the plasmatic membrane ( - Fig. 2). This increase may have a form of spikes, and additional calcium may come from store-operated calcium entry or store-independent pathways. ${ }^{43,45}$ The cytosolic calcium is uptaken into the

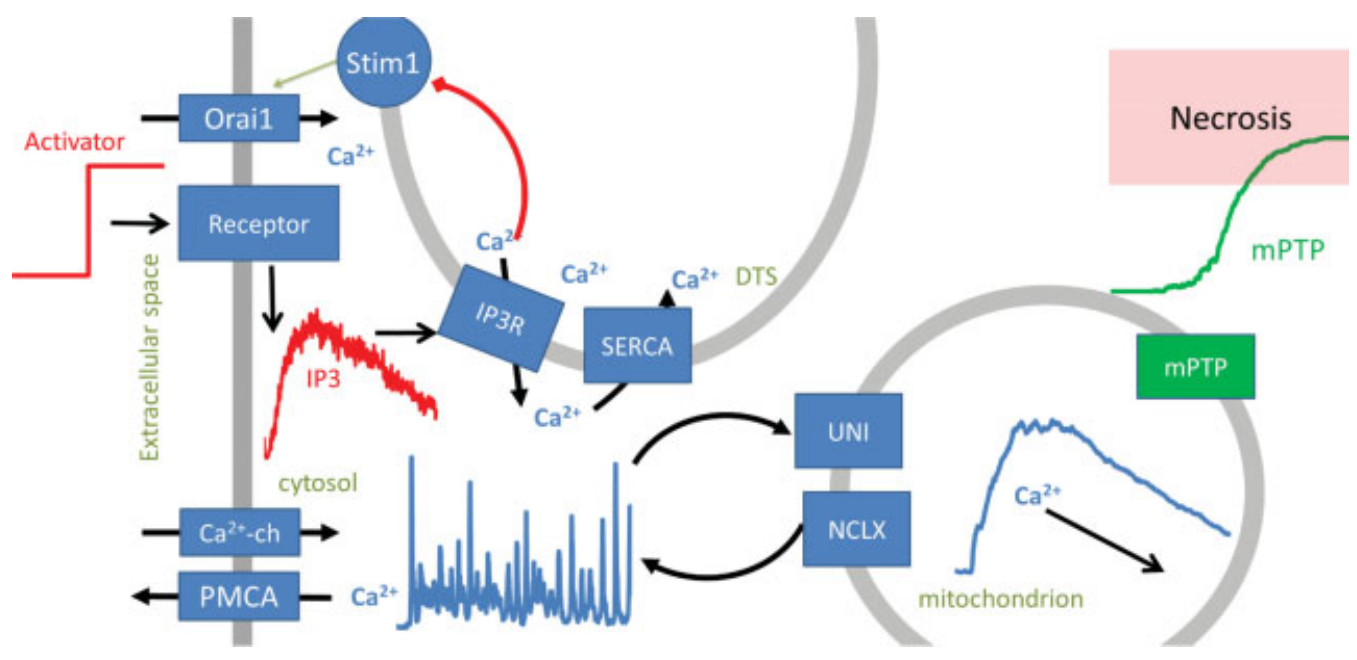

Fig. 2 Procoagulant platelet generation. Activation of platelets via PAR1 (protease-activated receptors) and/or PAR4 and/or glycoprotein VI leads to IP3 (inositol trisphosphate) increase, which initiates calcium spiking in the cytosol controlled by the DTS (dense tubular system). Sufficiently high calcium spikes lead to calcium uptake by the mitochondria, supposedly via calcium uniporter, so that calcium signal is "integrated" over time. If sufficient level is accumulated, then cyclophilin D-dependent mPTP (mitochondrial permeability transition pore) opening leads to the mitochondrial collapse and cell necrosis. IP3R, inositol trisphosphate receptor; SERCA, sarco/endoplasmic reticulum $\mathrm{Ca}^{2+}$. ATPase; STIM1, stromal interaction molecule 1; NCLX, Na/Li/Ca exchanger; UNI, calcium uniporter. 
mitochondria mainly via MCU, leading to the overloading of mitochondria matrix with calcium and mPTP opening, resulting in further cytosolic calcium increase and rapid ATP depletion as a result of inner mitochondrial membrane potential loss. The stable opening of MPTP in all mitochondria results in a typical necrotic cell death associated with rapid loss of plasma membrane integrity and collapse of any ion homeostasis. The sustained calcium increase at the supraphysiological level appears to be a consequence of this chain of events. ${ }^{39,43,44}$ PS externalization by anoctamin 6 , calpain-dependent cytoskeleton degradation with ballooning and microvesicle formation, and integrin inactivation appear to be mostly downstream events after the commitment to necrosis. Other signaling pathways may essentially modulate the upstream events leading to the platelet death and affect chances of a platelet to become procoagulant.

It is essential that the formation of procoagulant platelets is all-or-nothing process. Platelets are not predestined to become procoagulant: depending on the presence and concentration of thrombin (or thrombin receptor peptide), collagen (or collagen-related peptide, or convulxin), and ADP in the activation mixture, the number of platelets to become procoagulant can be from below $1 \%$ to above $90 \%{ }^{20}$ However, there could be factors that predispose platelets to become procoagulant rather than non-procoagulant: the reported ones include age, ${ }^{4}$ size, ${ }^{46,47}$ baseline calcium concentration, $^{39}$ and the number of mitochondria per platelet. $^{38}$

\section{Generation of Procoagulant Platelets In Situ}

The published data on the localization of both PS-positive platelets and fibrin in thrombi in vivo are rather controversial, and probably depend on the conditions of the experiments. The early studies on real-time confocal intravital imaging of laser-induced microvasculature thrombosis reported fibrin in the center of the thrombi, ${ }^{48}$ in line with the latest reports suggesting the core/shell concept of thrombus architecture in both microvasculature and macrovasculature. ${ }^{49,50}$ The first data on procoagulant platelets localization in thrombi came from Munnix et al, ${ }^{51}$ who described procoagulant platelets to be distributed as separate patches throughout the thrombi formed either in vitro or in vivo. However, at about the same time, other study reported that both procoagulant platelets and fibrin are colocalized in the core region of thrombi formed in vivo following a laser-induced injury of mesenteric venules. ${ }^{52}$ Another in vivo study showed that there are no procoagulant platelets following laser-induced injury of cremasteric arterioles in mice, but they are present and partially colocalized with fibrin in $\mathrm{FeCl} 3$-induced occlusive injury of the same vessels (though, their specific spatial distribution is hard to judge $).^{53}$ In marked contrast to previous studies on fibrin, another article on laser injury of mesenteric venules reported that fibrin formed a "coat" on the surface of platelet thrombus, rather than being in the center. ${ }^{54}$ Data coming from in vitro parallel-plate flow chamber experiments revealed that procoagulant platelets were also distributed on the surface of thrombus. ${ }^{14}$

Recent study on the origin of pulmonary thrombosis after gut ischemia revealed the importance of neutrophil interactions with procoagulant platelets on the surface of thrombi. $^{55}$ Interestingly, early reports on the structure of the hemostatic plugs in dogs and humans described both ballooned platelets and fibrin on the surface of these plugs. ${ }^{56,57}$ Another study reported predominant surface localization of PS-positive in thrombi formed on collagen under flow conditions in vitro and in small platelet aggregates formed in vitro without controlled flow. ${ }^{15}$ In the same study, TEM images of in vivo thrombus formed in response to ferric chloride-induced injury depicted ballooned platelets near the interface of thrombus and injured vessel wall. Detailed analysis of platelet plugs formed after penetrating injury of jugular vein revealed significant difference in both platelets and fibrin composition of the intraluminal and extravascular sides of the plug. ${ }^{58}$ Interestingly, numerous small spherical platelet fragments were described at the boundary of the injury site-possibly the fragments of procoagulant platelets.

Localization of procoagulant platelets on the surface of thrombi reported in many studies seemed paradoxical, as far as local biochemical microenvironment near thrombus surface is not expected to drive the formation of PS-positive, which requires potent activation. Recent study demonstrated predominant surface localization of PS-positive formed in two in vivo models of thrombosis and reported outward translocation of PS-positive during thrombus formation on collagen in vitro. ${ }^{59}$ Redistribution of procoagulant platelets to thrombus surface in vitro was driven by thrombus contraction, suggesting that the same mechanism might be responsible for surface localization of procoagulant platelets in vivo. Interestingly, redistribution of procoagulant platelets to thrombus periphery in vitro was followed by enhanced surface generation of fibrin, suggesting that mechanically induced redistribution of PS-positive may impact both spatial and temporal character of plasma coagulation reactions.

Thus, analysis of the published data regarding localization of procoagulant platelets in thrombi suggests that most of the in vivo models of thrombus formation in large vessels (like arteries), in vitro models of thrombus formation on collagen and hemostatic plugs formed in vivo, share a common feature of surface localization of procoagulant platelets. Enhanced deposition of fibrin on the thrombus surface, reported for some of these models, is likely mediated by surface distribution of procoagulant platelets; however, the details on the interplay between spatiotemporal features of procoagulant platelets formation and generation of both thrombin and fibrin are still poorly understood.

\section{Generation of Procoagulant Platelets in Patients}

Among the inherited platelet disorders, Scott's syndrome is probably the single well-known primary pathological consequence of impaired platelet procoagulant activity ${ }^{60}$ caused by a deficiency of anoctamin 6 , which normally exposes PS on 
the outer surface of activated platelets. ${ }^{61}$ However, decreased generation of procoagulant platelets was reported for a cohort of patients with bleeding, ${ }^{62}$ suggesting that they contribute in a much wider range of cases.

In contrast, Stormorken's syndrome, another inherited platelet disorder, is characterized by preactivated (with elevated surface PS exposure) and, at the same time, much less responsive to stimulation platelets ${ }^{63}$ due to increased basal calcium level caused by autosomal dominant mutations in the STIM1 (stromal interaction molecule 1) gene. ${ }^{64}$ Another platelet disorder potentially related to procoagulant platelets is Wiskott-Aldrich syndrome for which it has been shown that platelets readily expose PS via mitochondriadependent necrotic mechanism caused by their smaller size, which could contribute to the development of thrombocytopenia. ${ }^{38}$ An acquired platelet disease immune thrombocytopenia is characterized by elevated PS exposure on unstimulated platelets ${ }^{65,66}$ and increased resting intracellular calcium ${ }^{67}$ which likely contribute to the decreased platelet counts. Levels of circulating procoagulant platelets were significantly higher in colon cancer patients ${ }^{68}$ and patients with stage III/IV of gastric cancer ${ }^{69}$ compared with healthy control, which may play a role in cancer-associated venous thrombosis.

Procoagulant platelets can be considered biomarkers for the clinical assessment of thrombotic or bleeding tendency. Several studies have shown that a higher level of the procoagulant platelets was correlated with transient ischemic attack and stroke $e^{70,71}$ and with stroke recurrence. ${ }^{72,73}$ Moreover, elevated procoagulant platelet levels identify asymptomatic carotid stenosis patients at high risk for stroke or transient ischemic attack. ${ }^{74}$ Likewise, procoagulant platelet level has been suggested for use in risk stratification for stroke at 30 days after transient ischemic attack. ${ }^{75}$ In another study, procoagulant platelets rise after aneurysmal subarachnoid hemorrhage was associated with adverse clinical outcomes. ${ }^{76}$ On the contrary, a low level of the procoagulant platelets has been shown to be associated with more severe hemorrhage and increased mortality after spontaneous intracerebral hemorrhage. ${ }^{77-79}$

Studies in hemophilia A have shown that procoagulant platelet levels were significantly lower in hemophilia patients compared with healthy controls. Moreover, in hemophiliac patients with frequent bleeding episodes, the level of procoagulant platelets was relatively low. ${ }^{80}$

The level of procoagulant platelets can be affected not only by the disease itself but also by therapy. One example is the use of tyrosine kinase inhibitors for cancer treatment. It was shown that in dasatinib-treated patients with chronic myeloid leukemia, procoagulant platelet formation was significantly suppressed, ${ }^{81,82}$ which may be the cause of gastrointestinal bleeding on dasatinib treatment. ${ }^{83,84}$ Ibrutinib treatment further reduced procoagulant platelet formation upon strong stimulation, which was already reduced in patients with chronic lymphocytic leukemia which could also contribute to the development of bleeding. ${ }^{85}$ On the other hand, recent study suggests that procoagulant platelets are upregulated by desmopressin and may play a role in its mechanism of action of desmopressin. ${ }^{86}$ Another study $^{87}$ showed the ability of procoagulant platelets to bind factor VIIa and promote factor X activation by it, which may be a mechanism of action of recombinant-activated factor VII.

\section{Conclusions}

The existing evidence suggests that the main mechanism of procoagulant platelet generation is mitochondrially driven necrosis. It begins with "normal" platelet activation and intracellular calcium increase. This leads in turn to the accumulation of calcium by mitochondria. In some of the platelets (depending on size, age, and the number of mitochondria per platelet), this "normal" signaling results in mitochondrial collapse and necrotic process, with downstream formation of the procoagulant "coat" (or "cap") and integrin inactivation. Agonists under the influence of which formed PS-positive platelets have a significant effect on the presence of the procoagulant "coat" (or "cap"). But there is no convincing data that the type of activation affects the other functional properties of platelets or their fate. Interplay of thrombi, collagen (fibrin/fibrinogen), and ADP receptors determine the quantity of procoagulant platelets produced. Within thrombus, these properties lead to a redistribution of procoagulant platelets to the outside of the dense core as a result of contraction, which affects fibrin distribution in the thrombus. Currently, there is an active accumulation of knowledge about the relationship between the level of procoagulant platelets with various diseases and some types of therapy. However, it is still too early to say that we clearly understand the pathophysiological role of these platelets.

\section{Funding}

The authors were supported by the Russian Science Foundation grant 20-74-00133.

\section{Conflict of Interest}

The authors declare that they have no conflict of interest.

\section{References}

1 Heemskerk JWM, Mattheij NJA, Cosemans JMEM. Platelet-based coagulation: different populations, different functions. J Thromb Haemost 2013;11(01):2-16

2 Ahmad SS, London FS, Walsh PN. The assembly of the factor Xactivating complex on activated human platelets. J Thromb Haemost 2003;1(01):48-59

3 Dachary-Prigent J, Freyssinet JM, Pasquet JM, Carron JC, Nurden AT. Annexin $V$ as a probe of aminophospholipid exposure and platelet membrane vesiculation: a flow cytometry study showing a role for free sulfhydryl groups. Blood 1993;81(10): 2554-2565

4 Alberio L, Safa O, Clemetson KJ, Esmon CT, Dale GL. Surface expression and functional characterization of alpha-granule factor V in human platelets: effects of ionophore A23187, thrombin, collagen, and convulxin. Blood 2000;95(05):1694-1702

5 Dale GL, Friese P, Batar P, et al. Stimulated platelets use serotonin to enhance their retention of procoagulant proteins on the cell surface. Nature 2002;415(6868):175-179 
6 Agbani EO, Poole AW. Procoagulant platelets: generation, function, and therapeutic targeting in thrombosis. Blood 2017;130 (20):2171-2179

7 Reddy EC, Rand ML. Procoagulant phosphatidylserine-exposing platelets in vitro and in vivo. Front Cardiovasc Med 2020;7:15

8 van der Meijden PEJ, Heemskerk JWM. Platelet biology and functions: new concepts and clinical perspectives. Nat Rev Cardiol 2019;16(03):166-179

9 Tohidi-Esfahani I, Lee CSM, Liang HPH, Chen VMY. Procoagulant platelets: laboratory detection and clinical significance. Int J Lab Hematol 2020;42(Suppl 1):59-67

10 Baaten CCFMJ, Ten Cate H, van der Meijden PEJ, Heemskerk JWM. Platelet populations and priming in hematological diseases. Blood Rev 2017;31(06):389-399

11 Dale GL. Procoagulant platelets: further details but many more questions. [Internet]Arterioscler Thromb Vasc Biol 2017;37(09): 1596-1597

12 Webber AJ, Firkin BG. Two populations of platelets. Nature 1965; 205:1332-1332

13 Heemskerk JW, Vuist WM, Feijge MA, Reutelingsperger CP, Lindhout T. Collagen but not fibrinogen surfaces induce bleb formation, exposure of phosphatidylserine, and procoagulant activity of adherent platelets: evidence for regulation by protein tyrosine kinase-dependent Ca2+ responses. Blood 1997;90(07): 2615-2625

14 Abaeva AA, Canault M, Kotova YN, et al. Procoagulant platelets form an $\alpha$-granule protein-covered "cap" on their surface that promotes their attachment to aggregates. J Biol Chem 2013;288 (41):29621-29632

15 Agbani EO, van den Bosch MTJ, Brown E, et al. Coordinated membrane ballooning and procoagulant spreading in human platelets. Circulation 2015;132(15):1414-1424

16 Mitchell JL, Lionikiene AS, Fraser SR, Whyte CS, Booth NA, Mutch NJ. Functional factor XIII-A is exposed on the stimulated platelet surface. Blood 2014;124(26):3982-3990

17 Whyte CS, Swieringa F, Mastenbroek TG, et al. Plasminogen associates with phosphatidylserine-exposing platelets and contributes to thrombus lysis under flow. Blood 2015;125(16): $2568-2578$

18 Mattheij NJA, Gilio K, van Kruchten R, et al. Dual mechanism of integrin $\alpha$ IIb $\beta 3$ closure in procoagulant platelets. J Biol Chem 2013;288(19):13325-13336

19 Kulkarni S, Nesbitt WS, Dopheide SM, et al. Techniques to examine platelet adhesive interactions under flow. In: Gibbins JM, Mahaut-Smith MP, eds. Platelets and Megakaryocytes. New Jersey: Humana Press; 2004:165-186

20 Yakimenko AO, Verholomova FY, Kotova YN, Ataullakhanov FI, Panteleev MA. Identification of different proaggregatory abilities of activated platelet subpopulations. Biophys J 2012;102(10): 2261-2269

21 De Marco L, Mazzucato M, Masotti A, Ruggeri ZM. Localization and characterization of an alpha-thrombin-binding site on platelet glycoprotein Ib alpha. J Biol Chem 1994;269(09):6478-6484

22 Kempton CL, Hoffman M, Roberts HR, Monroe DM. Platelet heterogeneity: variation in coagulation complexes on platelet subpopulations. Arterioscler Thromb Vasc Biol 2005;25(04): 861-866

23 Panteleev MA, Ananyeva NM, Greco NJ, Ataullakhanov FI, Saenko EL. Two subpopulations of thrombin-activated platelets differ in their binding of the components of the intrinsic factor X-activating complex. J Thromb Haemost 2005;3(11):2545-2553

24 London FS, Marcinkiewicz M, Walsh PN. A subpopulation of platelets responds to thrombin- or SFLLRN-stimulation with binding sites for factor IXa. J Biol Chem 2004;279(19): 19854-19859

25 Dasgupta SK, Abdel-Monem H, Niravath P, et al. Lactadherin and clearance of platelet-derived microvesicles. [Internet]Blood 2009; 113(06):1332-1339
26 Sveshnikova AN, Balatskiy AV, Demianova AS, et al. Systems biology insights into the meaning of the platelet's dual-receptor thrombin signaling. J Thromb Haemost 2016;14(10):2045-2057

27 Kotova YN, Ataullakhanov FI, Panteleev MA. Formation of coated platelets is regulated by the dense granule secretion of adenosine 5 'diphosphate acting via the P2Y12 receptor. J Thromb Haemost 2008;6(09):1603-1605

28 Kotova YN, Podoplelova NA, Obydennyy SI, et al. Binding of coagulation factor XIII zymogen to activated platelet subpopulations: roles of integrin $\alpha \mathrm{IIb} \beta 3$ and fibrinogen. Thromb Haemost 2019;119(06):906-915

29 Shakhidzhanov SS, Shaturny VI, Panteleev MA, Sveshnikova AN. Modulation and pre-amplification of PAR1 signaling by ADP acting via the P2Y12 receptor during platelet subpopulation formation. Biochim Biophys Acta 2015;1850(12): $2518-2529$

30 Leon C, Ravanat C, Freund M, Cazenave JP, Gachet C. Differential involvement of the P2Y1 and P2Y12 receptors in platelet procoagulant activity. Arterioscler Thromb Vasc Biol 2003;23(10): 1941-1947

31 van der Meijden PE, Feijge MA, Giesen PL, Huijberts M, van Raak LP, Heemskerk JW. Platelet P2Y12 receptors enhance signalling towards procoagulant activity and thrombin generation: a study with healthy subjects and patients at thrombotic risk. Thromb Haemost 2005;93(06):1128-1136

32 Polgár J, Clemetson JM, Kehrel BE, et al. Platelet activation and signal transduction by convulxin, a C-type lectin from Crotalus durissus terrificus (tropical rattlesnake) venom via the p62/GPVI collagen receptor. J Biol Chem 1997;272(21):13576-13583

33 Ignatova AA, Ponomarenko EA, Polokhov DM, et al. Flow cytometry for pediatric platelets. Platelets 2019;30(04):428-437

34 Mammadova-Bach E, Ollivier V, Loyau S, et al. Platelet glycoprotein VI binds to polymerized fibrin and promotes thrombin generation. Blood 2015;126(05):683-691

35 Remenyi G, Szasz R, Friese P, Dale GL. Role of mitochondrial permeability transition pore in coated-platelet formation. Arterioscler Thromb Vasc Biol 2005;25(02):467-471

36 Schoenwaelder SM, Yuan Y, Josefsson EC, et al. Two distinct pathways regulate platelet phosphatidylserine exposure and procoagulant function. Blood 2009;114(03):663-666

37 Sveshnikova AN, Ataullakhanov FI, Panteleev MA. Compartmentalized calcium signaling triggers subpopulation formation upon platelet activation through PAR1. Mol Biosyst 2015;11(04): 1052-1060

38 Obydennyi SI, Artemenko EO, Sveshnikova AN, et al. Mechanisms of increased mitochondria-dependent necrosis in WiskottAldrich syndrome platelets. Haematologica 2020;105(04): 1095-1106

39 Obydennyy SI, Sveshnikova AN, Ataullakhanov FI, Panteleev MA. Dynamics of calcium spiking, mitochondrial collapse and phosphatidylserine exposure in platelet subpopulations during activation. J Thromb Haemost 2016;14(09):1867-1881

40 Artemenko EO, Yakimenko AO, Pichugin AV, Ataullakhanov FI, Panteleev MA. Calpain-controlled detachment of major glycoproteins from the cytoskeleton regulates adhesive properties of activated phosphatidylserine-positive platelets. Biochem J 2016;473(04):435-448

41 Reddy EC, Wang H, Christensen H, et al. Analysis of procoagulant phosphatidylserine-exposing platelets by imaging flow cytometry. Res Pract Thromb Haemost 2018;2(04):736-750

42 Alberio L, Ravanat C, Hechler B, Mangin PH, Lanza F, Gachet C. Delayed-onset of procoagulant signalling revealed by kinetic analysis of COAT platelet formation. Thromb Haemost 2017;117 (06):1101-1114

43 Aliotta A, Bertaggia Calderara D, Zermatten MG, et al. Sodiumcalcium exchanger reverse mode sustains dichotomous ion fluxes required for procoagulant COAT platelet formation. Thromb Haemost 2021;121(03):309-321 
44 Abbasian N, Millington-Burgess SL, Chabra S, Malcor JD, Harper MT. Supramaximal calcium signaling triggers procoagulant platelet formation. Blood Adv 2020;4(01):154-164

45 Harper MT, Londoño JE, Quick K, et al. Transient receptor potential channels function as a coincidence signal detector mediating phosphatidylserine exposure. [Internet]Sci Signal 2013;6(281): ra50

46 Rukoyatkina N, Begonja AJ, Geiger J, Eigenthaler M, Walter U, Gambaryan S. Phosphatidylserine surface expression and integrin alpha IIb beta 3 activity on thrombin/convulxin stimulated platelets/particles of different sizes. Br J Haematol 2009;144 (04):591-602

47 Handtke S, Wesche J, Palankar R, Greinacher A, Thiele T. Function of large and small platelets differs, depending on extracellular calcium availability and type of inductor. Thromb Haemost 2020; 120(07):1075-1086

48 Falati S, Gross P, Merrill-Skoloff G, Furie BC, Furie B. Real-time in vivo imaging of platelets, tissue factor and fibrin during arterial thrombus formation in the mouse. Nat Med 2002;8(10): $1175-1181$

49 Stalker TJ, Traxler EA, Wu J, et al. Hierarchical organization in the hemostatic response and its relationship to the platelet-signaling network. Blood 2013;121(10):1875-1885

50 Welsh JD, Poventud-Fuentes I, Sampietro S, Diamond SL, Stalker TJ, Brass LF. Hierarchical organization of the hemostatic response to penetrating injuries in the mouse macrovasculature. J Thromb Haemost 2017;15(03):526-537

51 Munnix ICA, Kuijpers MJE, Auger J, et al. Segregation of platelet aggregatory and procoagulant microdomains in thrombus formation: regulation by transient integrin activation. Arterioscler Thromb Vasc Biol 2007;27(11):2484-2490

52 Hayashi T, Mogami H, Murakami Y, et al. Real-time analysis of platelet aggregation and procoagulant activity during thrombus formation in vivo. Pflugers Arch 2008;456(06):1239-1251

53 Hua VM, Abeynaike L, Glaros E, et al. Necrotic platelets provide a procoagulant surface during thrombosis. Blood 2015;126(26): 2852-2862

54 Kamocka MM, Mu J, Liu X, et al. Two-photon intravital imaging of thrombus development. J Biomed Opt 2010;15(01):016020

55 Yuan Y, Alwis I, Wu MCL, et al. Neutrophil macroaggregates promote widespread pulmonary thrombosis after gut ischemia. Sci Transl Med 2017;9(409):eaam5861

56 Jørgensen L, Borchgrevink CF. The platelet plug in normal persons. Acta Pathol Microbiol Scand 1963;57:427-437

57 Hovig T, Rowsell HC, Dodds WJ, Jorgensen L, Mustard JF. Experimental hemostasis in normal dogs and dogs with congenital disorders of blood coagulation. Blood 1967;30(05):636-668

58 Tomaiuolo M, Matzko CN, Poventud-Fuentes I, Weisel JW, Brass LF, Stalker TJ. Interrelationships between structure and function during the hemostatic response to injury. Proc Natl Acad Sci U S A 2019;116(06):2243-2252

59 Nechipurenko DY, Receveur N, Yakimenko AO, et al. Clot contraction drives the translocation of procoagulant platelets to thrombus surface. Arterioscler Thromb Vasc Biol 2019;39(01):37-47

60 Zwaal RFA, Comfurius P, Bevers EM. Scott syndrome, a bleeding disorder caused by defective scrambling of membrane phospholipids. Biochim Biophys Acta 2004;1636(2-3):119-128

61 Rosing J, Bevers EM, Comfurius $\mathrm{P}$, et al. Impaired factor $\mathrm{X}$ and prothrombin activation associated with decreased phospholipid exposure in platelets from a patient with a bleeding disorder. Blood 1985;65(06):1557-1561

62 Daskalakis M, Colucci G, Keller P, et al. Decreased generation of procoagulant platelets detected by flow cytometric analysis in patients with bleeding diathesis. Cytometry B Clin Cytom 2014;86 (06):397-409

63 Misceo D, Holmgren A, Louch WE, et al. A dominant STIM1 mutation causes Stormorken syndrome. Hum Mutat 2014;35 (05):556-564
64 Böhm J, Laporte J. Gain-of-function mutations in STIM1 and ORAI1 causing tubular aggregate myopathy and Stormorken syndrome. Cell Calcium 2018;76:1-9

65 Winkler J, Kroiss S, Rand ML, et al. Platelet apoptosis in paediatric immune thrombocytopenia is ameliorated by intravenous immunoglobulin. Br J Haematol 2012;156(04):508-515

66 Ignatova AA, Demina IA, Ptushkin VV, et al. Evolution of platelet function in adult patients with chronic immune thrombocytopenia on romiplostim treatment. Br J Haematol 2019;187(02): e38-e42

67 Martyanov AA, Morozova DS, Sorokina MA, et al. Heterogeneity of integrin $\alpha$ IIb $\beta 3$ function in pediatric immune thrombocytopenia revealed by continuous flow cytometry analysis. Int J Mol Sci MDPI AG 2020;21:3035

68 Zhao L, Bi Y, Kou J, Shi J, Piao D. Phosphatidylserine exposingplatelets and microparticles promote procoagulant activity in colon cancer patients. J Exp Clin Cancer Res 2016;35:54

69 Yang C, Ma R, Jiang T, et al. Contributions of phosphatidylserinepositive platelets and leukocytes and microparticles to hypercoagulable state in gastric cancer patients. Tumour Biol 2016;37 (06):7881-7891

70 Prodan CI, Dale GL. Coated-platelets in ischemic stroke - potential insight into the etiology of stroke subtypes. Int J Stroke 2008;3 (04):249-250

71 Prodan CI, Vincent AS, Dale GL. Coated-platelet levels are elevated in patients with transient ischemic attack. Transl Res 2011;158 (01):71-75

72 Prodan CI, Stoner JA, Cowan LD, Dale GL. Higher coated-platelet levels are associated with stroke recurrence following nonlacunar brain infarction. J Cereb Blood Flow Metab 2013;33(02): 287-292

73 Kirkpatrick AC, Stoner JA, Dale GL, Prodan CI. Elevated coatedplatelets in symptomatic large-artery stenosis patients are associated with early stroke recurrence. Platelets 2014;25(02):93-96

74 Kirkpatrick AC, Tafur AJ, Vincent AS, Dale GL, Prodan CI. Coatedplatelets improve prediction of stroke and transient ischemic attack in asymptomatic internal carotid artery stenosis. Stroke 2014;45(10):2995-3001

75 Kirkpatrick AC, Vincent AS, Dale GL, Prodan CI. Coated-platelets predict stroke at 30 days following TIA. Neurology 2017;89(02): 125-128

76 Ray B, Pandav VM, Mathews EA, et al. Coated-platelet trends predict short-term clinical outcome after subarachnoid hemorrhage. Transl Stroke Res 2018;9(05):459-470

77 Prodan CI, Vincent AS, Padmanabhan R, Dale GL. Coated-platelet levels are low in patients with spontaneous intracerebral hemorrhage. Stroke 2009;40(07):2578-2580

78 Prodan CI, Vincent AS, Dale GL. Coated platelet levels correlate with bleed volume in patients with spontaneous intracerebral hemorrhage. Stroke 2010;41(06):1301-1303

79 Prodan CI, Stoner JA, Dale GL. Lower coated-platelet levels are associated with increased mortality after spontaneous intracerebral hemorrhage. Stroke 2015;46(07):1819-1825

80 Saxena K, Pethe K, Dale GL. Coated-platelet levels may explain some variability in clinical phenotypes observed with severe hemophilia. J Thromb Haemost 2010;8(05):1140-1142

81 Deb S, Boknäs N, Sjöström C, Tharmakulanathan A, Lotfi K, Ramström S. Varying effects of tyrosine kinase inhibitors on platelet function-a need for individualized CML treatment to minimize the risk for hemostatic and thrombotic complications? Cancer Med 2020;9(01):313-323

82 Mezei G, Debreceni IB, Kerenyi A, et al. Dasatinib inhibits coatedplatelet generation in patients with chronic myeloid leukemia. Platelets 2019;30(07):836-843

83 Kostos L, Burbury K, Srivastava G, Prince HM. Gastrointestinal bleeding in a chronic myeloid leukaemia patient precipitated by dasatinib-induced platelet dysfunction: Case report. Platelets 2015;26(08):809-811 
84 Quintás-Cardama A, Kantarjian H, Ravandi F, et al. Bleeding diathesis in patients with chronic myelogenous leukemia receiving dasatinib therapy. Cancer 2009;115(11):2482-2490

85 Dmitrieva EA, Nikitin EA, Ignatova AA, et al. Platelet function and bleeding in chronic lymphocytic leukemia and mantle cell lymphoma patients on ibrutinib. J Thromb Haemost 2020;18(10): 2672-2684

86 Colucci G, Stutz M, Rochat S, et al. The effect of desmopressin on platelet function: a selective enhancement of procoagulant COAT platelets in patients with primary platelet function defects. Blood 2014;123(12):1905-1916

87 Kjalke M, Kjellev S, Rojkjaer R. Preferential localization of recombinant factor VIIa to platelets activated with a combination of thrombin and a glycoprotein VI receptor agonist. J Thromb Haemost 2007;5(04):774-780

88 Podoplelova NA, Sveshnikova AN, Kotova YN, et al. Coagulation factors bound to procoagulant platelets concentrate in cap structures to promote clotting. Blood 2016;128(13):1745-1755 